\title{
EVOLUÇÃO TECNOLÓGICA NO SETOR VITIVINÍCOLA: VÍNCULOS COM A EMBRAPA UVA E VINHO'
}

\author{
TECHNOLOGICAL DEVELOPMENTS IN THE WINERY SECTOR: LINKS WITH \\ EMBRAPA GRAPE AND WINE
}
Carla Cristina Rosa de Almeida* Vinícius Salatin Corrêa** Suzana da Silva Soares ${ }^{* *}$

\section{Resumo}

Os avanços tecnológicos do setor vitivinícola permitiram a expansão geográfica do cultivo da uva nas últimas décadas. Nesse processo, pretende-se analisar o papel da Embrapa Uva e Vinho, abordando a relevância que a interação com o setor produtivo proporciona à evolução tecnológica do setor e, em particular, seus reflexos sobre a produção de uva no estado de Mato Grosso, através dos vínculos com a Agropecuária Melina. Em termos teóricos, apoia-se nas teorias evolucionárias sobre interação do sistema acadêmico com empresas. Além disso, esta pesquisa caracterizou-se pela natureza empírica, qualitativa e descritiva, utilizando a técnica de estudo de caso. A estratégia de coleta de dados abrangeu pesquisa documental e pesquisa de campo, sendo a última realizada de forma presencial junto a Agropecuária Melina, localizada no estado de Mato Grosso. Conclui-se que o impacto das pesquisas no setor produtivo em estudo é positivo, já que o padrão tecnológico atual do setor vitivinícola está relacionado à trajetória das próprias instituições públicas de pesquisa, responsáveis pela geração de conhecimento científico. Ademais, esse impacto é maior em virtude da difusão tecnológica e absorção do conhecimento pelas firmas, ambas promovidos pela interação, sobretudo com a Embrapa Uva e Vinho.

Palavras-chave: Cooperação tecnológica; Agropecuária Melina; Embrapa Uva e Vinho.

\footnotetext{
"Doutora em Economia pela Universidade Federal de Pernambuco (UFPE). Professora do Departamento de Ciências Econômicas - Universidade Federal de Mato Grosso- Campus de Cuiabá.

${ }^{* *}$ Técnico em Assessoria e Gerenciamento Empresarial - ETEC Taquaritinga - SP. Tecnólogo em Produção Industrial - FATEC Taquaritinga - SP. Graduando em Engenharia de Produção Universidade Federal de São Carlos - Campus Sorocaba

${ }^{* * \star}$ Graduada em Engenharia de produção Agroindustrial pela Universidade do Estado de Mato Grosso (UNEMAT).

1 Os autores agradecem a receptividade e as informações fornecidas pela equipe da Melina Agropecuária, em especial ao Sr. Michel Leplus. Também agradecemos a Robinson Ferreira (Ló), pela contribuição na pesquisa de campo.
}

Revista de Estudos Sociais | Ano 2017, N. 38, V. 19, Pag. 13 


\begin{abstract}
Technological advances in the viticulture allowed the geographical expansion of grape production in recent decades. In this process, we intend to explore the relevance of the Embrapa Grape \& Wine for technological developments in the sector and, in particular, its effects on grape production in the state of Mato Grosso, through linkages with the Agropecuária Melina. In theoretical terms, it's based on the evolutionary theories about the academic system and firms' interaction. In addition, this research was characterized by its empirical, qualitative and descriptive nature, using the technique of case study. The strategy for data collection included desk research and fieldwork at the Agropecuária Melina, located in Nova Mutum (MT). We conclude that the impact of research in the productive sector under study is positive, in view of the fact that the current technological standard of the grape culture is related to the trajectory of the public research institutions, which are responsible for the generation of scientific knowledge. Moreover, this impact is greater because of the technological diffusion and knowledge absorption by firms, both promoted by the interaction, especially with Embrapa Grape \& Wine.
\end{abstract}

Keywords: Technological cooperation; Agropecuária Melina; Embrapa Grape \& Wine.

Código JEL: 032

\title{
1 Introdução
}

Até a década de 60, a viticultura esteve restrita às regiões Sul e Sudeste do país. Os principais avanços tecnológicos do setor, como o desenvolvimento de novas cultivares, de técnicas e sistemas de manejo das videiras, permitiram a expansão geográfica do cultivo da uva para outras regiões. (CAMARGO et al., 2011). Assim, "a atividade ocupa uma área de aproximadamente 83.700 hectares, com uma produção anual variando entre 1.300 e 1.400 mil toneladas", com o Rio Grande do Sul como maior produtor. (MELLO, 2011 apud CAMARGO et al., 2011, p. 145). Em 2010, os principais produtos foram uva de mesa, $57 \%$ da produção, seguido do suco concentrado e vinho, $43 \%$.

Nesse processo, é importante analisar o papel da Embrapa e de seus projetos de melhoramento da videira; abordando a relevância que a interação com o setor produtivo proporciona a evolução tecnológica do setor e, em particular, seus reflexos sobre a produção de uva no estado de Mato Grosso, através dos vínculos com a Agropecuária Melina. Assim, esta pesquisa tem como finalidade analisar os vínculos do setor vitivinícola com a Embrapa Uva e Vinho, através de análise qualitativa de estudo de caso. Em termos teóricos, apoia-se na nas teorias evolucionárias sobre interação do sistema acadêmico com empresas.

Na sequência desta introdução, na segunda seção, comenta-se sobre o sistema de inovação agrícola e a trajetória tecnológica do setor vitivinícola, com destaque para a atuação da Embrapa. Na terceira seção, têm-se a análise de estudo de caso qualitativo de cooperação tecnológica, mais especificamente,

Revista de Estudos Sociais | Ano 2017, N. 38, V. 19, Pag. 14 
entre a Embrapa Uva e Vinho e a Agropecuária Melina, na qual a empresa é uma das parceiras responsáveis pelos ensaios de validação agronômica e industrial das cultivares desenvolvidas pela instituição de pesquisa. Por fim, a quarta seção traz as considerações finais.

Espera-se que o trabalho possa contribuir para a área de conhecimento ao apresentar um estudo empírico acerca da importância da interação e da busca tecnológica das instituições públicas de pesquisa para 0 desenvolvimento econômico, a partir da geração e transbordamento do conhecimento que, nesse caso, abrangeu diferentes regiões do país.

2 Sistemas de inovação e mudança tecnológica na agricultura: o caso do setor vitivinícola

\subsection{Sistema de inovação agrícola brasileiro}

A ciência econômica tem discutido de forma recorrente a relação entre desenvolvimento econômico e capacidade de geração e aplicação de conhecimentos científicos e tecnológicos. Os diferentes atores que atuam diretamente ou indiretamente na inovação - universidades, institutos de pesquisa, empresas e governos - assim como os arcabouços regulatório, legal e financeiro, formam um arranjo institucional que a literatura neoschumpeteriana denomina de sistema nacional de inovação (SNI).

Nesse contexto, a interação dos meios acadêmicos e empresarial contribui para os processos de aprendizagem e aumenta o impacto das pesquisas no setor produtivo. Isso decorre do entendimento de que as firmas, por estarem mais próximas do mercado, são as maiores responsáveis pela inovação. Dessa forma, diante das divergências entre os objetivos dos diversos agentes econômicos no tocante a busca de conhecimentos, as características do SNI podem estimular ou restringir a transferência de informações e, consequentemente, as trajetórias tecnológicas nacionais e/ou setoriais.

No caso do Brasil, observa-se um SNI imaturo, com vínculos parciais entre firmas e instituições de ensino e pesquisa. Como consequência, o grau de interação universidade-empresa diferencia-se conforme área de conhecimento e setor produtivo, tanto quanto persiste a desigualdade espacial da infraestrutura de ciência, tecnologia e inovação (CT\&I), com forte concentração de recursos financeiros e humanos na região Sudeste (SUZIGAN, ALBUQUERQUE, 2011; ALMEIDA et al. 2011).

Diferente do que ocorre em outros setores, os vínculos entre agricultura e instituições científicas representam um caso de êxito nacional promovido, em grande monta, pelas ações públicas relacionadas à pesquisa agrícola. A trajetória institucional permitiu a consolidação de um Sistema de Inovação Setorial, cuja infraestrutura científica e tecnológica é referência em nível internacional, com evidente contribuição das instituições de ensino e pesquisa para o desenvolvimento da agricultura no país, seja através da formação de recursos humanos ou da inovação técnica via pesquisa e desenvolvimento (P\&D) tecnológico (CAMPOLINA, 2016; TEIXEIRA, CLEMENTE, BRAGA, 2013; SUZIGAN, ALBUQUERQUE, 2011).

Revista de Estudos Sociais | Ano 2017, N. 38, V. 19, Pag. 15 
As primeiras escolas agrícolas, bem como as pioneiras instituições de pesquisa, como o Instituto Agronômico de Campinas (IAC), datam o final do século XIX, enquanto algumas universidades com vocação na área de ciências agrárias surgiram no início do século XX (TEIXEIRA, CLEMENTE, BRAGA, 2013). E embora tenham sido criadas diversas instituições voltadas à pesquisa agrícola a partir da primeira metade do século XX, a implantação da Embrapa marcou a consolidação do P\&D agrícola nacional. Desde então, a instituição tem assumido papel central na pesquisa agropecuária e na transferência de tecnologia aos produtores, com importante pesquisas na fertilidade do solo e em melhoramento genético de culturas específicas.

A ascensão das novas tecnologias - tecnologias de informação e comunicação (TICS), biotecnologia, nanotecnologia, etc. - impôs a multidisciplinaridade como elemento para implementação de mudança técnica e tem tornado a trajetória de inovação na agricultura cada vez mais dependente da inovação em geral (VIEIRA et al., 2015). Tal complexidade dificulta o enquadramento do setor agrícola em um regime tecnológico específico, sendo insuficiente tratar a agricultura como um setor dominado pelo fornecedor (POSSAS, SALLES-FILHO, SILVEIRA, 1996).

Em parte, tal dificuldade deriva do fato de que, nas indústrias relacionadas a produção agrícola, é possível encontrar todas as taxonomias de Pavitt ${ }^{2}$. Além disso, as estratégias tecnológicas diferem significativamente a depender do segmento produtivo analisado $e$, concomitantemente, os processos de aprendizagem estão sujeitos a melhorias tecnológicas, que criam competitividade a uma parcela das firmas e, logo, desequilíbrios competitivos permanentes (oligopolização).

Esse cenário impôs novos desafios para a formulação e implementação de políticas públicas de pesquisa e também ao papel que a Embrapa tem assumido ao longo dos anos como coordenadora do sistema setorial de inovação, com perda de hegemonia recente na pesquisa em alguns segmentos agrícolas. Cabe destacar que, após os anos 2000, novos atores, sobretudo multinacionais vinculadas aos segmentos mais competitivos, passaram a atuar no espaço agropecuário nacional através da realização de P\&D, inclusive nas áreas de melhoramento genético, historicamente liderada pela Embrapa (BONACELLI, FUCK, CASTRO, 2015).

Outros elementos somam-se aos problemas de coordenação do Sistema de Inovação Agrícola Brasileiro $(\mathrm{SIA})^{3}$, tais como entraves burocráticos, disputas por temas de pesquisa e recursos financeiros e humanos com outras instituições públicas - agravadas pelo desaparelhamento das OEPAs promovidos pelos estados (BONACELLI, FUCK, CASTRO, 2015) - e pela

\footnotetext{
${ }^{2}$ Conforme a taxonomia de Pavitt (1984 apud POSSAS, SALLES-FILHO, SILVEIRA, 1996), os diferentes setores podem ser classificados conforme seu regime tecnológico, sendo que no caso daqueles ligados a agricultura, tem-se: baseados em ciência (sementes e pesticidas), intensivos em escala (fertilizantes químicos), fornecedores especializados (máquinas agrícolas) e dominados pelo fornecedor (indústria alimentícia).

3 Como parte da política agrícola nacional direcionada ao P\&D agrícola, o Ministério de Agricultura e Reforma Agrária instituiu, em 1992, o Sistema Nacional de Pesquisa Agropecuária (SNPA) sob coordenação da Embrapa e com participação das Organizações Estaduais de Pesquisa Agropecuária (OEPAs), instituições de ensino superior, institutos de pesquisa e outras organizações públicas e privadas (BONACELLI, FUCK, CASTRO, 2015).
}

Revista de Estudos Sociais | Ano 2017, N. 38, V. 19, Pag. 16 
persistência do instituto nas mesmas diretrizes da década de 1970, com foco no melhoramento vegetal (VIEIRA et al., 2015).

Contudo, a despeito das mudanças no cenário concorrencial do agronegócio, que vem colocando desafios ao próprio futuro da pesquisa agrícola nacional e, consequentemente, da posição do país no mercado mundial, pode-se afirmar que o êxito das parcerias e da competitividade atual da agricultura não são frutos exclusivos de vantagens competitivas naturais, mas de ações vinculadas de diversos agentes, como é o caso do segmento vitivinícola, exposto a seguir.

\subsection{Embrapa Uva e Vinho: vínculos com a trajetória tecnológica vitivinícola}

\subsubsection{Histórico}

A iniciativa pioneira de melhoramento genético da videira no país ocorreu a partir de 1938, através do Instituto Agronômico de Campinas (IAC) ${ }^{4}$. Em 1937, surge o Laboratório Central de Enologia, com sede no Rio de Janeiro e estações distribuídas nos estados do Rio Grande do Sul, São Paulo e Minas Gerais. No início dos anos 40, foi fundada a Estação de Enologia de Bento Gonçalves e, ao longo do tempo, doações de lotes e aquisições pela Prefeitura Municipal e pelo Instituto Rio-grandense do Vinho ao Governo Federal contribuíram para a expansão da área geográfica para uso exclusivo da Estação, atingindo uma extensão de 100 hectares. No ano de 1969, passou a ser chamada de Estação Experimental de Bento Gonçalves. (EMBRAPA UVA E VINHO, 2014).

Assim, a partir da década de 60, o IAC lançou e difundiu várias cultivares e porta enxertos adaptados às diferentes regiões do país.

O processo de difusão das cultivares do IAC deu-se pelo fornecimento de pequenas quantidades de material propagativo aos produtores que, após algum tempo de observação, multiplicavam e difundiam as novas cultivares, passando de viticultor a viticultor. (CAMARGO, 2008, p. 37).

Antes disso, a viticultura brasileira dependia totalmente de cultivares importadas (CAMARGO, 2008, p. 38) e esteve restrita ao Sul e Sudeste. Os principais avanços tecnológicos do setor foram promovidos pelo processo de aparelhamento institucional para apoio ao setor vitivinícola, iniciado nos anos 30. O desenvolvimento de novas variedades, de técnicas e sistemas de manejo das videiras permitiu a expansão geográfica do cultivo da uva para outras regiões (CAMARGO et al., 2011).

Com a criação da Embrapa em 1973, a Estação Experimental de Bento Gonçalves foi incorporada como uma de suas unidades - Unidade de Execução de Pesquisa de Âmbito Estadual (UEPAE) de Bento Gonçalves - e em 1985, passou a ser denominada de Centro Nacional de Pesquisa de Uva e

\footnotetext{
4 "Os primeiros trabalhos de melhoramento genético da videira, no Brasil, foram iniciativas pessoais" de viticultores (PAZ, 1898; SOUSA, 1959; SANTOS NETO, 1955 apud CAMARGO, 2008, p. 37).
}

Revista de Estudos Sociais | Ano 2017, N. 38, V. 19, Pag. 17 
Vinho (CNPUV). Atualmente, a unidade mencionada é a sede da Embrapa Uva e Vinho (EMBRAPA UVA E VINHO, 2014).

Mais tarde, foram criados locais que se tornaram uma espécie de semiinstitutos da Embrapa, denominados de estações experimentais. São estas: a Estação Experimental de Fruticultura de Clima Temperado (EFCT), localizada em Vacaria (RS); e a Estação Experimental de Viticultura Tropical (EVT), localizada em Jales (SP). Tais unidades surgem como forma de extensão dos trabalhos realizados pela sede e para atender às necessidades da variedade de cultivares que se adaptem às diferentes regiões, além de pesquisas relacionadas a outras frutas, tais como maçã, pera e, mais recentemente, as pequenas frutas 5 .

A criação de uma estação em Jales ocorreu devido à demanda do setor na região, firmada através de um convênio entre o Ministério da Agricultura/Embrapa, a Secretaria da Agricultura de Jales, a Associação dos Viticultores da região de Jales (AVIRJAL) e a Prefeitura Municipal de Jales. Dos 16 hectares de área da EVT, oito são ocupados por parreirais, sendo que o centro possui o maior Banco Ativo de Germoplasma de videira do país, adaptadas às condições de clima tropical. Em virtude da sua atuação em clima tropical, é com essa unidade que a Agropecuária Melina mantém suas relações atuais de parceria.

\subsection{Projeto de Melhoramento Genético 'Uvas do Brasil'}

Desde 1977, a Embrapa Uva e Vinho tem buscado a adaptação dos materiais às diferentes condições edafoclimáticas brasileiras, através de diversos projetos, entre esses, os que incluem melhoramento genético da videira. Tal programa tem como objetivo obter novas cultivares de uva para vinho, suco e mesa, que tenham maior qualidade, produtividade e resistência às principais doenças que atacam a cultura da videira, como o míldio principalmente em lugares úmidos - e o oídio - que geralmente ocorre em ambientes com temperaturas amenas e com uma baixa umidade relativa do ar.

Atualmente, o Programa, intitulado 'Projeto Uvas do Brasil', combina métodos clássicos de melhoramento - "Banco de Germoplasma, (...) introdução de novos materiais, seleção massal, seleção clonal e hibridações" e ferramentas de biologia avançada (UVAS DO BRASIL, 2014a). O Programa mantém cooperação com universidades, institutos de pesquisa e empresas, distribuídas pelo país nas diversas regiões, como demonstrado no Quadro 1.

\footnotetext{
5 "No caso particular das pequenas frutas de clima temperado, as primeiras ações de pesquisa e desenvolvimento desenvolvidas pela Unidade deram-se em 1997", no caso do morango, a partir das bases físicas Encosta Superior do Nordeste e Campos de Cima da Serra, no Rio Grande do Sul. (HOFFMANN, 2007, p. 35).
}

Revista de Estudos Sociais | Ano 2017, N. 38, V. 19, Pag. 18 
Quadro 1 - Empresas e/ou Instituições que estabelecem parceiras com o Projeto Uvas do Brasil vinculado a Embrapa Uva e Vinho e a respectiva localização

\begin{tabular}{|l|c|}
\hline \multicolumn{1}{|c|}{ Empresas, Cooperativas e Associações } & Localização \\
\hline Melina Agropecuária & Nova Mutum - MT \\
\hline Casa Valduga & Bento Gonçalves - RS \\
\hline Casa Gilioli & Flores da Cunha - RS \\
\hline Vinícola Perini & Farroupilha - RS \\
\hline Frutacor LTDA & Pirapora - MG \\
\hline Cooperativa Agrícola de Pirapora (CAP) & Jales - SP \\
\hline Cooperativa Mista dos Produtores de Jales (CAMPRJ) & Rolândia - PR \\
\hline Cooperativa Agropecuária Rolândia (COROL) & Santa Teresa - ES \\
\hline Associação dos Vitivinicultores de Santa Teresa (AVIST) & Pirapora - MG \\
\hline Associação dos Usuários do Projeto Pirapora (AUPPI) & Localização \\
\hline \multicolumn{1}{|c|}{ Universidades e/ou Instituições de Pesquisa } & Porto Alegre - RS \\
\hline $\begin{array}{l}\text { Centro de Biotecnologia da Universidade Federal do Rio } \\
\text { Grande do Sul }\end{array}$ & Brasília - DF \\
\hline Embrapa Recursos Genéticos e Biotecnologia & Petrolina - PE \\
\hline Embrapa Semiárido & Campinas - SP \\
\hline Embrapa Produtos e Mercado & São Paulo - SP \\
\hline Instituto de Botânica de São Paulo & Salvador - BA \\
\hline Universidade do Estado da Bahia (UNEB) & Lavras - MG \\
\hline Universidade Federal de Lavras - Departamento de Biologia & Porto Alegre - RS \\
\hline $\begin{array}{l}\text { Universidade Federal do Rio Grande do Sul - Departamento de } \\
\text { Genética }\end{array}$ &
\end{tabular}

Fonte: Adaptado de Uvas do Brasil (2014b).

Relato de um dos pesquisadores da instituição enfatiza a importância das parcerias para desenvolvimento e difusão da tecnologia no setor.

A experiência acumulada ao longo do processo de difusão das novas cultivares da Embrapa evidencia que a adoção depende não só do valor da tecnologia, mas também, e principalmente, da sua adequada utilização, e de programas de desenvolvimento em parceria com os setores produtivo, agroindustrial e comercial, para oferecer ao mercado produtos de excelência e em volume adequado. Paralelamente, são necessárias, estratégias de marketing para informar ao consumidor sobre a nova alternativa de consumo, suas características e vantagens, a exemplo do que normalmente é feito com qualquer produto novo (CAMARGO, 2008, p. 40).

Nos últimos anos, muitas variedades de uvas de mesa e de uvas para elaboração de vinhos e de sucos foram desenvolvidas e lançadas pelo programa. De maneira geral, estas cultivares caracterizam-se por apresentar adaptação as diferentes regiões do país. A Figura 1 apresenta as variedades desenvolvidas pela Embrapa, com o respectivo ano de lançamento no mercado. 


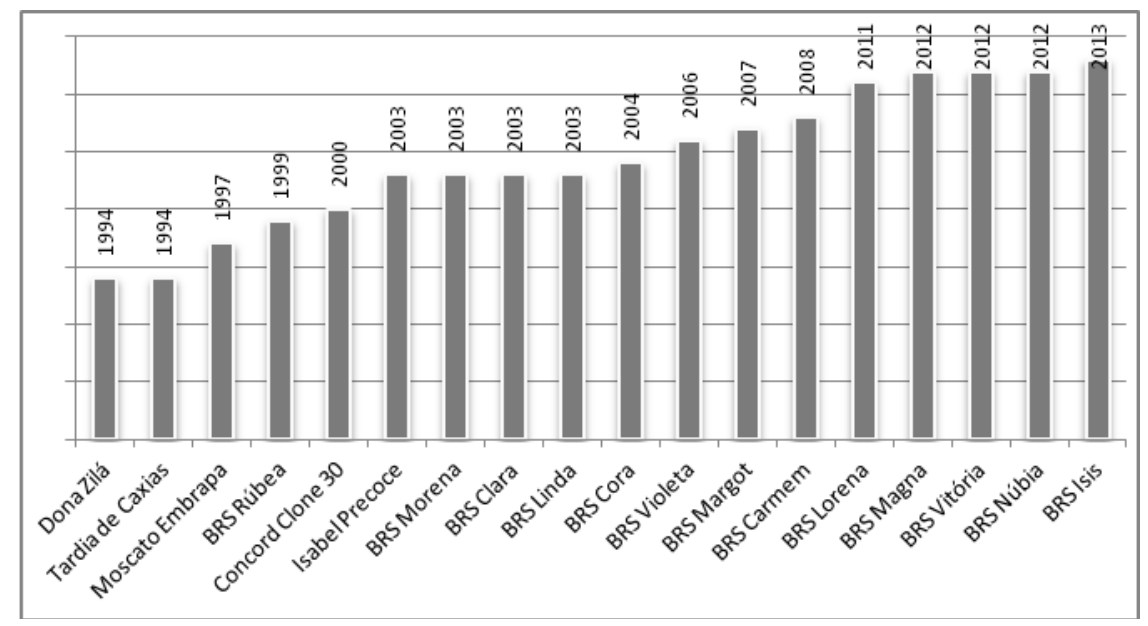

Figura 1 - Espécies lançadas pelo Projeto Uvas do Brasil, 1994 a 2013 Fonte: Adaptado de Uvas do Brasil (2014).

O projeto colaborou diretamente para o avanço da produção nas zonas tropicais, tais como Centro-Oeste e Nordeste, a partir dos anos 90, com 0 desenvolvimento de "tecnologia para a produção de uvas americanas e híbridas em climas quentes, bastante diversa daquela utilizada para as cultivares de Vitis vinifera" (HOFFMANN, CAMARGO, MAIA, 2005). De acordo com Hoffmann, Camargo e Maia (2005),

(...) atendendo à demanda de produtores de diferentes regiões do país, foram implantadas unidades de observação de novas e de tradicionais cultivares deste grupo em Minas Gerais, no Mato Grosso do Sul, no Mato Grosso, em Goiás, no Norte do Paraná e em Pernambuco. Este trabalho, realizado em estreita parceria com a iniciativa privada, proporcionou significativos avanços no conhecimento e na tecnologia de produção, estimulando à implantação de novos polos vitícolas voltados à produção de uvas para suco e para vinho de mesa nestas regiões.

Atualmente, existe uma variabilidade de material genético, com mais de 20 cultivares Vits Vinifera e mais de 40 do tipo americanas, "incluindo castas de Vitis labrusca, Vitis bourquina e de híbridas interespecíficas" (CAMARGO et al., 2011, p. 145). As cultivares Isabel Precoce, BRS Cora e BRS Violeta são a base da produção nos estados de clima tropical (CAMARGO, 2008). Por sua vez, "como uva americana de mesa, a Niágara Rosada é praticamente a única alternativa, com presença marcante nos vinhedos de todas as regiões produtoras. É uma uva de fácil manejo no campo e de grande aceitação no mercado" (CAMARGO et al., 2011, p. 146).

\subsection{Padrões de inovação do setor vitivinícola}

O padrão de inovação no setor vinícola no Brasil é marcado por tecnologia estabilizada e difundida, com baixas oportunidades tecnológicas. $O$ segmento agrícola beneficia-se da evolução da biotecnologia e da genética, mediante a introdução de novas cultivares, desenvolvidas pelas instituições de pesquisa, em particular a Embrapa Uva e Vinho. Ao mesmo tempo, sua

Revista de Estudos Sociais | Ano 2017, N. 38, V. 19, Pag. 20 
evolução tecnológica também se beneficia das inovações realizadas pelos fornecedores de insumos químicos e de máquinas agrícolas (CARVALHO et al., 2006; FARIAS, 2010).

Um exemplo de mudança no processo produtivo induzida por fornecedores de maquinário é a mecanização dos vinhedos, inclusive de pequenos produtores na região da Campanha do Rio Grande do Sul.

Os vinhedos de castas finas para vinho estão sendo implantados em sistema de condução em espaldeiras, adaptados à mecanização da maioria das práticas culturais, incluindo poda, poda verde e colheita, além das pulverizações. (...) Também foram implantados vinhedos em outros sistemas de condução (...) no Vale do São Francisco, (...) São Paulo e (...) norte do Paraná. (CAMARGO, 2008, p. 147).

Contudo, a principais inovações ocorreram nas técnicas de cultivo e foram relevantes para a expansão geográfica da produção da uva e melhoria da qualidade da fruta, tais como reconversão dos vinhedos tradicionais para espaldeiras, "técnicas modernas de diagnose e monitoramento nutricional, sistemas de irrigação e fertirrigação, sistemas de monitoramento e controle sanitário (...). Na produção de uvas de mesa, algumas regiões investiram no cultivo protegido com o uso de tela ou cobertura plástica". (CAMARGO, 2008, p. 146).

Em termos de inovação de produto, estudo sobre os empreendimentos do Rio Grande do Sul mostrou que a maior parte das empresas não possui setor para análise e desenvolvimento do vinho ou suco. Além disso, esses produtos caracterizam-se pela padronização, com as empresas menores imitando as inovações realizadas pelas líderes, sem realização de pesquisa de mercado sobre a aceitação do produto a ser lançado. As inovações ocorrem, então, de maneira informal, por meio de 'tentativa-e-erro' (FARIAS, 2010).

Por sua vez, sobressaem-se as estratégias de inovação para sustentabilidade dos negócios, tais como busca de novos mercados, equiparação aos padrões tecnológicos ao nível internacional (Normas ISO), inovações de produto e estratégias de marketing, incluindo Indicação Geográfica (FARIAS, 2010; MENDES et. al., 2012; SLUSZZ, PADILHA, 2008). Para Farias (2010, p. 5), o desafio do setor não está nas mudanças organizacionais, mas na necessidade de maiores investimentos nos insumos, particularmente nas videiras, que determina diretamente a qualidade do produto final.

Em geral, o padrão de apropriabilidade tecnológica do setor vitivinícola vincula-se a adoção de cultivares desenvolvidas por investimentos estatais em conhecimento científico gerado de forma exógena à empresa, por meio do IAC e da Embrapa. Contudo, são diferentes as formas em que a tecnologia é absorvida pelas empresas, já que dependem e estão ligadas à sua trajetória tecnológica. Segundo Carvalho et al. (2006), na atividade agrícola, destacamse os mecanismos legais; a competência própria para exploração produtiva e a competência coletiva. No cultivo da uva ocorrem os dois primeiros, já que a apropriabilidade coletiva é típica de setores de intenso dinamismo e altas oportunidades tecnológicas. Nesse contexto, o licenciamento das cultivares é

Revista de Estudos Sociais | Ano 2017, N. 38, V. 19, Pag. 21 
disponibilizado para todas as empresas do setor, mas as que participam do projeto junto a Embrapa apresentam vantagens, pois se apropriam de elementos tácitos, uma vez que participam dos ensaios e testes das novas cultivares em suas próprias dependências, com forte acúmulo de conhecimento acerca de sua exploração produtiva.

Outra fonte privada de inovação que tem sido explorada pelos produtores rurais de uva e seus derivados são as instituições para certificação e rastreabilidade do produto, que tem impulsionado as mudanças organizacionais, que é o caso da Melina, e será discutido adiante. Além disso, também com intuito de agregar valor aos produtos derivados da uva e enfrentar barreiras não tarifárias no mercado externo, os produtores têm optado pela diferenciação através da Indicação Geográfica, que consiste na "garantia quanto à origem de um produto e/ou suas qualidades e características regionais" (FRONZAGLIA et al., 2010, p. 5). Essa diferenciação pode ser subdividida em Indicação de Procedência (IP) e Denominação de Origem (DO), que são concedidas pelo Instituto Nacional da Propriedade Industrial (INPI)6.

Novamente, observa-se a participação da Embrapa e o efeito do transbordamento do conhecimento. A Embrapa instalou laboratórios de pesquisa para dar suporte às indicações geográficas de vinhos no Rio Grande do Sul, em parceria com as unidades Clima Temperado (Pelotas) e Solos (Rio de Janeiro). O primeiro local a implantar a indicação geográfica foi o Vale dos Vinhedos, localizado na Serra Gaucha (RS), para vinhos finos e espumantes. Por meio de cooperação entre as empresas do local, estas obtiveram o IP em 2002, depois de um trâmite de 5 anos, e o DO em 20097 (CAMARGO et al., 2011; FRONZAGLIA et al., 2010). Após o sucesso dos pioneiros, a estratégia tem sido adotada em outras regiões produtoras de vinhos (Pinto Bandeira, Altos Montes, Monte Belo, Vales da Uva Goethe) e uvas de mesa (Vale do Submédio São Francisco), que já obtiveram as IPs (INPI, 2014).

Por fim, cabe ressaltar que o surgimento de novas tecnologias tem atribuído mudanças na trajetória tecnológica da agricultura, reduzindo a importância dos recursos naturais como vantagens competitivas. No segmento de vinhos, por exemplo, tal fato revela-se na mudança do padrão de concorrência mediante a entrada de novos países no mercado mundial, reduzindo a participação dos países europeus tradicionais8. No Brasil, por sua vez, o Mercosul acirrou a concorrência ${ }^{9}$ e alterou as estratégias dos produtores locais. Principalmente no caso de pequenos produtores, a diferenciação de

\footnotetext{
6 "IP que é caracterizada por ser o nome geográfico conhecido pela produção, extração ou fabricação de determinado produto, (...) de forma a possibilitar a agregação de valor quando indicada a sua origem (...); e DO cuida do nome geográfico que designe produto ou serviço cujas qualidades ou características se devam exclusiva ou essencialmente ao meio geográfico, incluídos fatores naturais e humanos" (FRONZAGLIA et al., 2010, p. 5).

7 Vale dos Vinhedos foi a primeira região não europeia a conquistar o reconhecimento pela Comunidade Europeia, como região de origem controlada (ROESE, 2008 apud FRONZAGLIA et. al., 2010).

8 Países como Austrália, África do Sul, China, Estados Unidos, Argentina e Chile tem ganhado espaço no mercado mundial com seus chamados 'vinhos tecnológicos', contribuindo para a queda da participação da produção mundial dos vinhos europeus, que passou de $77,9 \%$, nos anos 1990, para 64,2\%, entre 2005 e 2007 (JUK, FUCK, 2015).

${ }_{9}^{9}$ As importações aumentaram de 19,4\%, em 1993, para 46\%, em 2000 (JUK, FUCK, 2015).
}

Revista de Estudos Sociais | Ano 2017, N. 38, V. 19, Pag. 22 
produto tem sido utilizada para superar desvantagens de custos de produção em um mercado dominado por grandes firmas (oligopólio competitivo ${ }^{10}$ ) e predominantemente padronizado (JUK, FUCK, 2015).

\section{Estudo de caso: interação da Melina Agropecuária com a Embrapa}

Esta pesquisa caracterizou-se pela natureza empírica, qualitativa e descritiva, utilizando a técnica de estudo de caso para analisar a atuação da Embrapa Uva e Vinho junto às empresas do setor vitivinícola, em particular, à Agropecuária Melina, localizada no município de Nova Mutum, estado de Mato Grosso.

Como critério de seleção, estabeleceu-se que a empresa pertencesse ao setor no qual a interação mostra-se mais intensa no estado, a saber, entre o setor agrícola e a área de ciências agrárias. Para tanto, foi realizada uma análise da conectividade academia-indústria, por meio de surveys de grupos de pesquisa e empresas, realizados em 2008 e 2009, respectivamente, dos quais foram extraídos alguns casos considerados relevantes para serem estudados, entre esses, o caso entre a Melina e a Embrapa.

Em geral, a estratégia de coleta de dados abrangeu pesquisa documental e pesquisa de campo. Na pesquisa documental, foram coletadas informações disponibilizadas pela própria Embrapa Uva e Vinho, no site e em artigos de autoria de seus pesquisadores. Sobre o papel dessa instituição para outras empresas que participam da rede de interações, recorreu-se a estudos de casos publicados em eventos e periódicos científicos. Levou-se em consideração também evidências de outros estudos acerca dos padrões de interação no estado de Mato Grosso, também no setor agrícola, para estudo comparativo.

Acerca da interação com a Melina, as informações foram coletadas em duas etapas, no ano de 2013, sendo que a principal fonte foi a percepção de um dos sócios e também gerente administrativo da empresa acerca da parceria e do papel da Embrapa no processo de implantação da mesma e de suas inovações. Inicialmente, os contatos foram à distância, por telefone e e-mail, além de obtenção de informações através de pesquisa documental no site da empresa, da Embrapa e outros sites de notícias. Num segundo momento, realizou-se uma visita à empresa Melina, para entrevistar o proprietário através de questionário semiestruturado, além de realização de visita técnica junto a área de cultivo da uva e a planta industrial de processamento.

\subsection{Caracterização da Melina Agropecuária Ltda.}

A empresa Melina Agropecuária Ltda. está a $50 \mathrm{~km}$ do perímetro urbano do município de Nova Mutum, situado na Região Norte mato-grossense, conforme Figura 2. Essa região é caracterizada pelos recentes crescimentos econômico e demográfico, oriundos da atividade agroindustrial, com destaque para o cultivo de grãos.

10 Enquadram-se nessa classificação setores com baixas barreiras à entrada, no qual convivem grandes empresas, que detém significativa participação dos mercados, com um elevado número de empresas marginais (CARVALHO, 2000).

Revista de Estudos Sociais | Ano 2017, N. 38, V. 19, Pag. 23 


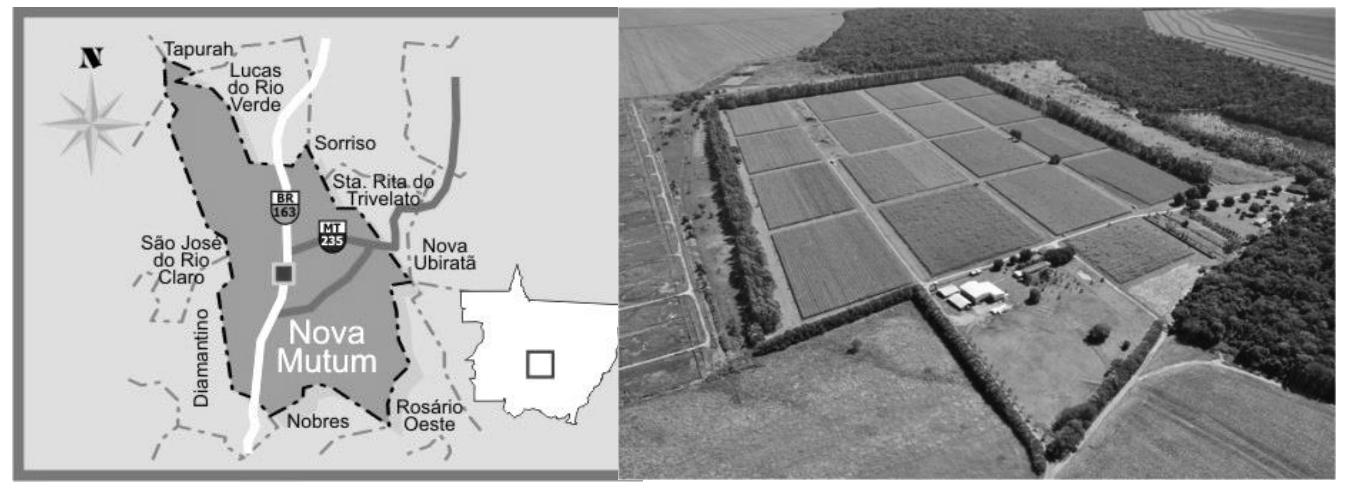

Figura 2 - aLimites Geográficos de Nova Mutum (MT) e bVista aérea da Melina Agropecuária

Fonte: a Portal Mato Grosso (2013); b Melina Agropecuária (2013).

A Fazenda Melina iniciou suas atividades em 1983, num primeiro momento, com a atividade pecuária, particularmente com o cruzamento industrial de raças europeias. Os sócios, dois irmãos franceses, influenciados pela vivência numa região especializada em uva e vinho'11, bem como de contatos com pesquisadores da Embrapa Uva e Vinho, optaram pela produção de uva. Assim, em 1998, realizaram "o plantio do primeiro hectare de uva a título experimental, foram mais de 14 variedades diferentes, inclusive uvas viníferas, para futura elaboração de vinho, espumante e vinagre". (AGROPECUÁRIA MELINA, 2013).

A empresa iniciou atuando apenas no setor agrícola e, em 2001, realizou integração vertical a jusante, a partir da construção de planta industrial para processamento do suco de uva e da primeira colheita para fins comerciais. A verticalização é uma estratégia muito praticada no setor, tanto para reduzir o risco da reconversão dos vinhedos, quanto para o controle da qualidade da matéria-prima (FARIAS, 2010). Devido a dificuldades mercadológicas, oriundas de custos logísticos devido à localização, nos primeiros anos, o suco foi comercializado através de parcerias com vinícolas do Rio Grande do Sul e com redes de supermercados que vendiam com marca própria. (PROTAS, CAMARGO, 2011).

Ao todo, a Melina Agropecuária conta com 35 funcionários, sendo que nove são direcionados exclusivamente para a fabricação do suco e os demais atuam na atividade agrícola. Devido à distância da propriedade em relação à cidade, a maioria dos funcionários reside na própria fazenda, que dispõe de quartos, cozinha, área para cultivo de hortas para consumo próprio e uma pequena área de lazer. O último espaço construído recentemente foi a sala de treinamento, diante da percepção da necessidade de um local para desenvolver e capacitar seu corpo colaborativo, pois encontram dificuldade para a locomoção de seu pessoal para treinamentos externos à empresa.

Atualmente, a propriedade possui 35 hectares de parreirais, subdivididos em cinco hectares para cultivo da uva Niágara Rosada, destinada exclusivamente à comercialização de uva de mesa, e os demais hectares estão

${ }^{11}$ Região de Bourdeux, no Sul da França.

Revista de Estudos Sociais | Ano 2017, N. 38, V. 19, Pag. 24 
voltados para as espécies utilizadas para a fabricação do suco, sendo 20 hectares para Isabel Precoce e 10 para BRS Violeta.

Em média, a produtividade é de 25 toneladas por hectare, sendo 0 principal empreendimento vitivinícola do estado. A safra da uva ocorre uma vez ao ano, especificamente entre agosto e outubro, período de seca na região, com uma produção de cerca de mil toneladas. Inicialmente, tentou-se realizar até três safras por ano, mas observou-se que tal procedimento não é adequado para o regime de chuvas da região. O problema está na concentração das chuvas, que causa perda da qualidade da uva. A umidade em excesso prejudica o fruto, desencadeando o 'inchaço', seguido do rompimento da casca e uma consecutiva perda do nível de açúcar, bem como aumenta a possibilidade de proliferação de pragas, o que acarretava em uso de agrotóxicos (EMBRAPA LANÇA ..., 24/11/12). O procedimento de apenas uma safra é inclusive indicado pela Embrapa, especificamente em relação a cultivar Isabel, mas também é válido para as outras variedades.

(...) no caso da viticultura tropical, principalmente nas regiões Sudeste e Centro-Oeste (...) não é possível a realização de dois ciclos durante o período de estiagem; ou o início do primeiro ciclo ou a colheita do segundo ocorrem em pleno período das águas, expondo a cultura às dificuldades de controle fitossanitário ou à perda de qualidade causada pelo excesso de chuvas, respectivamente. (CAMARGO, 2004).

Por sua vez, a fábrica tem capacidade produtiva para beneficiamento de 10 mil garrafas de suco por dia, considerando o tamanho de 500 mililitros $^{12}$. Para atender o mercado de suco durante o período de entressafra, é utilizado um sistema de armazenamento a vácuo do suco, em recipientes próprios, para engarrafamento ao longo do ano. O destino do Suco de Uva Melina é cerca de $40 \%$ para consumo interno e $60 \%$ para fora do estado de Mato Grosso.

A fazenda conta com um sistema mecanizado de irrigação, concentrado em uma bomba que é controlada por um pequeno painel computadorizado que permite vários ajustes, tais como ajustes de vazão, sensor de chuva, programação de irrigação por determinado horário/período, dentre outras funções. É importante ressaltar que, diferente do cultivo de outras frutas, o cultivo da uva tem sua irrigação realizada da metade do caule para baixo, justamente para evitar a umidade em excesso das folhas e frutas, que aumenta a probabilidade de doenças. A Figura 3 demonstra o sistema de irrigação.

12 Em 2013, passaram a comercializar também a garrafa de 1 litro.

Revista de Estudos Sociais | Ano 2017, N. 38, V. 19, Pag. 25 


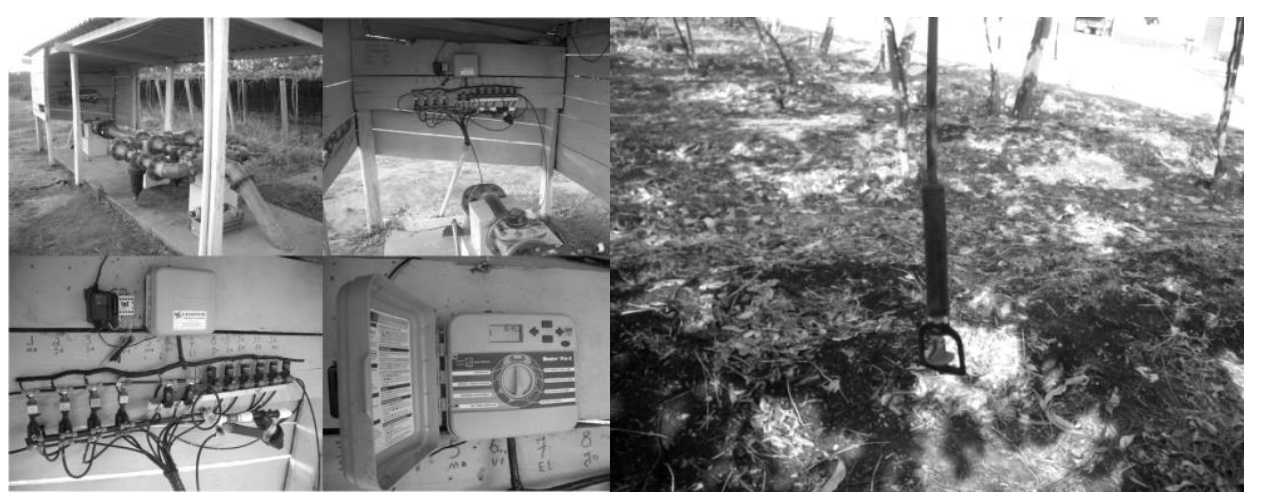

Figura 3 - Sistema mecanizado de irrigação e aspersor utilizado na irrigação dos parreirais

Fonte: Pesquisa de campo (2013).

Como é comum no plantio da uva, a Melina conta com um planejamento microclimático, chamado quebra-vento, cercando os parreirais por uma plantação de eucaliptos. Atrelado a esse mecanismo natural de defesa, em um ponto estratégico da fazenda, há a instalação de um anemômetro que auxilia na mensuração da velocidade do vento, para que as medidas de proteção possam ser tomadas. O quebra-vento e o anemômetro podem ser vistos na Figura 4.

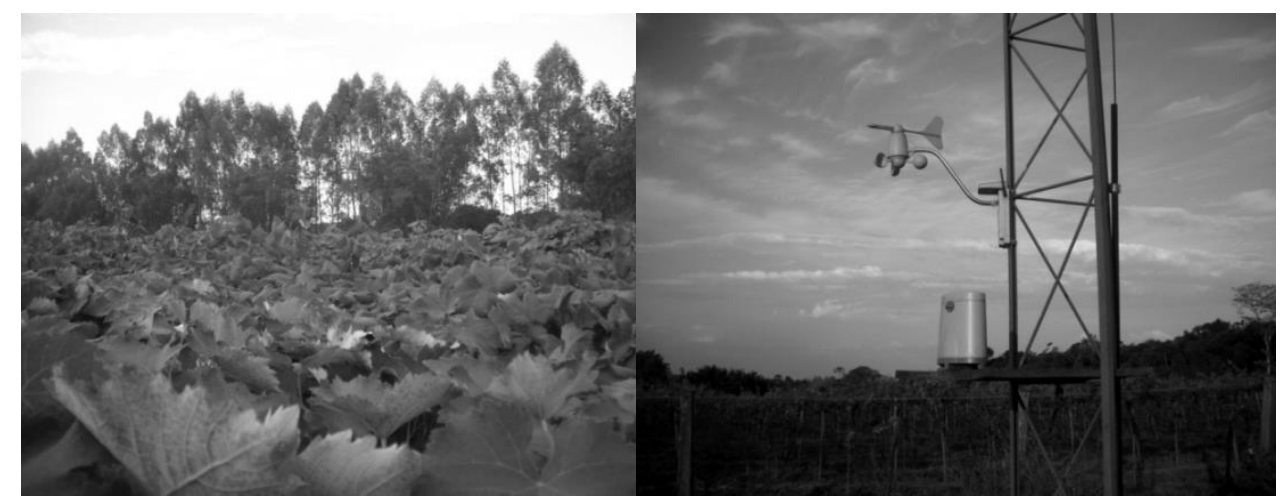

Figura 4 - Efeito 'quebra-vento' dos eucaliptos cercando os parreirais e anemômetro

Fonte: Pesquisa de campo (2013).

\subsection{Estratégias de inovação da Melina: cooperação com Embrapa Uva e Vinho}

Dos processos inovativos que tem ocorrido no setor, a empresa realiza a inserção de novas cultivares, mudanças nas técnicas e manejo e tem seguido a tendência de busca por certificação, em conformidade ao padrão setorial do país, como apresentado em Farias (2010) e Camargo et. al. (2010). Em geral, o setor vitivinícola utiliza principalmente instituições públicas de pesquisa como fonte de informação para as inovações, em virtude do ativo papel da Embrapa Uva e Vinho no que tange ao desenvolvimento e licenciamento das variedades de videiras. Nesse contexto, as inovações de processo na atividade agrícola da Melina praticamente não são desencadeadas pelos fornecedores privados como ocorre em diversos segmentos agrícolas. Em parte, esse aspecto devese as características do processo produtivo, manual e com uso de poucos

Revista de Estudos Sociais | Ano 2017, N. 38, V. 19, Pag. 26 
insumos químicos, em contraposição ao que ocorre no mercado grãos, principal cultura do estado de Mato Grosso. (CARVALHO et al., 2006).

A possibilidade de mecanização da colheita, conforme visão do sócio entrevistado, não é interessante para a empresa, sendo que o problema não se deve à aquisição do maquinário (disponível via importação), mas à necessidade de alterar o layout da plantação, substituindo a plantação horizontal pela vertical. Por consequência, acarretaria uma diminuição da área com exposição à luz solar, reduzindo a produtividade.

Por outro lado, foi uma mudança organizacional - detenção do Selo de Garantia de Origem Carrefour para o Suco Melina - que causou diversas mudanças no período, que englobaram ambos os setores: agrícola e industrial. A decisão desencadeou um processo longo de inovações incrementais no processo produtivo e na organização do trabalho, iniciado em 2004, para obtenção do selo em 2011.

Apesar não ter concorrentes em termos de produção em Mato Grosso, são várias as marcas de suco de uva oferecidas no estado, inclusive de grandes empresas, que usufruem de economias de escala e escopo. Dado que o mercado é um oligopólio competitivo, com baixas oportunidades de diferenciação, a empresa tem a rastreabilidade e certificação como uma garantia de qualidade e boas práticas na produção.

Dessa forma, os proprietários decidiram realizar uma série de inovações de processos, que atendessem aos quesitos necessários para 0 reconhecimento da qualidade, tais como o uso eficiente da água - encontravase em fase de construção uma miniestação de tratamento de água, com o objetivo de tratar grande parte da água utilizada no processo de industrialização - e a mínima utilização de produtos químicos - que são avaliados durante a auditoria. Para maior controle quanto à contaminação no processo produtivo, também se construiu um orifício de acesso que interliga a parte externa e interna da fábrica para movimentação da matéria-prima, das garrafas de vidro utilizadas como embalagem e do descarte dos resíduos, o que resultou em uma significativa redução da entrada de funcionários no interior da fábrica, como mostra a Figura 5.

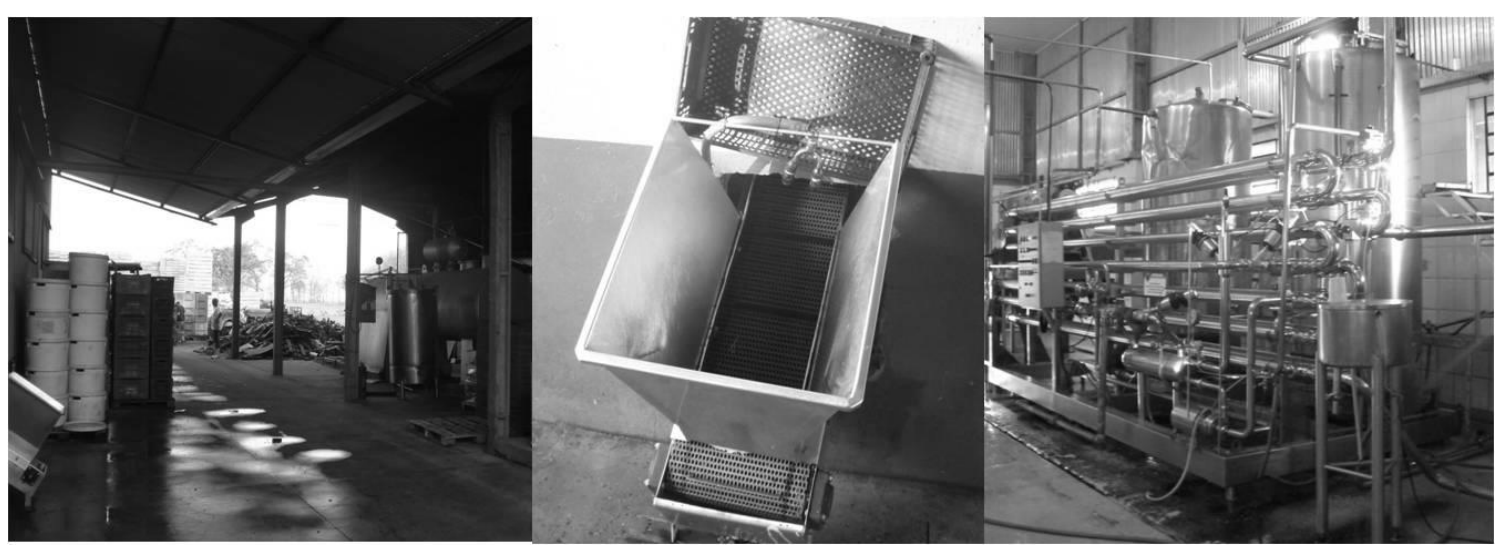

Figura 5 - Ambiente externo da fábrica (à esq.), janela de inserção da matériaprima e embalagens (centro) e ambiente interno da fábrica durante limpeza (à dir.)

Fonte: Pesquisa de campo, 2013.

Revista de Estudos Sociais | Ano 2017, N. 38, V. 19, Pag. 27 
Dentre os principais problemas apontados em relação ao processo produtivo, o entrevistado apontou a falta de mão de obra qualificada para 0 trabalho. A recente opção de contratação dos menores aprendizes, que poderiam ser futuros colaboradores formados com a cultura da empresa, é dificultada pela regulamentação da contratação, particularmente, pela frequência semanal obrigatória em curso de formação, diante da distância da fazenda em relação à cidade.

Em geral, a principal inovação na empresa é a adoção de novas variedades de videiras, que ocorre de acordo com ciclo inovativo do setor vinculado às pesquisas da Embrapa. Nesse contexto, a cooperação tecnológica tem papel fundamental, inclusive foi fator decisivo para a própria criação da empresa. A ideia inicial de realizar o cultivo da uva e fabricação do suco integral da fruta surgiu através da amizade de um dos proprietários da Melina com um pesquisador da Embrapa Uva e Vinho localizada em Bento Gonçalves. Posteriormente, o vínculo estendeu-se para a unidade de Jales, a EVT, e é com esta unidade em que ocorrem as atividades cooperativas com pesquisadores da área de genética, melhoramento de plantas e biologia molecular. Como mencionado, a EVT é a responsável pelos projetos que envolvem a produção de uva em climas tropicais.

Apenas o primeiro plantio comercial de uva a ser cultivado pela Melina não foi realizado em parceria com a Embrapa. Depois disso, ocorreu o fortalecimento desta interação e a fazenda transformou-se numa espécie de campo experimental da instituição, responsável pelos ensaios de validação agronômica e industrial das diversas variedades da fruta.

Dessa forma, diversas cultivares foram testadas, tanto as que já estavam no mercado, com o intuito de averiguar a adaptação ao clima tropical, quanto as recentemente desenvolvidas pela Embrapa e ainda não comercializadas. Normalmente, o lançamento de uma nova variedade de uva leva cerca de 10 anos entre o período de pesquisa e inovação ${ }^{13}$. Após os experimentos, caso constate-se que as características e propriedades da uva são adequadas para a produção do suco integral, amostras do suco são mantidas engarrafadas por dois anos, para então ocorrer a comercialização. Esse período é definido levando em consideração o tempo de validade comercial do produto.

Dentre os diversos experimentos, a Melina participou de projetos em que as cultivares não se mostraram adaptada ao clima local, como foi o caso da cultivar BRS Carmem, por exemplo. Tal variedade passou, então, a ser recomendada para cultivo na Serra Gaúcha e no Norte do Paraná para elaboração de suco e vinho de mesa. (CAMARGO, MAIA, RITSCHEL, 2008).

Durante o desenvolvimento de uma nova variedade, esta passa por testes de qualidade, sendo alguns realizados pela Embrapa - os que dependem de laboratório, e outros pela empresa, no que se refere ao processo produtivo. Em caso positivo, as parreiras tornam-se matrizes, de onde poderão

${ }_{13}$ De acordo com os pesquisadores, a BRS Cora, por exemplo, levou 12 anos até o seu lançamento, "foram oito de pesquisa em laboratório e quatro em experimentos na Fazenda Melina. (...) se os cruzamentos não fossem destinados a regiões tropicais, (...) os resultados demorariam ainda mais (...)." Em campo, quatro seleções de uva se destacaram, mas depois de avaliações agronômicas, somente a Cora se sobressaiu (PERES, 2004).

Revista de Estudos Sociais | Ano 2017, N. 38, V. 19, Pag. 28 
ser extraídas as mudas da nova cultivar, com o direito de propriedade pertencente à Embrapa.

Conforme relato do sócio, os principais critérios que norteiam a tomada de decisão da Melina em relação à adoção de uma variedade são: o aumento da produtividade, o aumento do nível de açúcar, o aumento do nível de acidez, a resistência contra doenças e a redução do trabalho no cultivo - menor necessidade da repoda, otimizando-se, dessa forma, o tempo e a mão de obra na colheita e manutenção dos parreirais.

Em geral, antes da divulgação dos resultados das pesquisas, ocorre um acompanhamento rígido de seu desenvolvimento junto à Fazenda Melina, com visitas técnicas de pesquisadores da Embrapa, tanto da EVT, quanto da sede. $\mathrm{Na}$ medida em que surgem variedades melhores, ocorre reconversão dos parreirais. Foi o que ocorreu com a primeira variedade em que a Melina participou do desenvolvimento, a BRS Cora. Lançada em 2004, na época, a adoção ocorreu por dois motivos principais: aumento da coloração e produtividade, sobretudo tendo em vista que as variedades com maior poder de coloração e até então disponíveis adaptavam-se melhor ao clima do Sul do país (PERES, 2004).

No ano de 2006, ocorre lançamento da variedade Violeta, que atualmente responde por $20 \%$ da uva utilizada na produção de suco, juntamente com a Isabel Precoce, que responde por $80 \%$. A Isabel possui alto teor de açúcar, mas o uso da Violeta faz-se necessário para acrescentar a coloração típica dos sucos de uva no país. Em 2012, é lançada a variedade BRS Magna, que se mostrou superior às variedades utilizadas para fabricação de suco em clima quente e úmido, apresentando-se mais doce, com maior poder de coloração e maior produtividade do que as utilizadas para a mesma finalidade no Rio Grande do Sul (EMBRAPA LANÇA ..., 24/11/12).

No entanto, no período de pesquisa de campo, a cultivar BRS Magna ainda não estava sendo utilizada na produção para fins comerciais. Concomitante, a parceria entre a Embrapa e a Melina já colocava em fase experimental mais duas variedades de videira. Ambas se encontravam em processo de cultivo e sem frutos, mantidas na condição de 'segredo tecnológico', inclusive com proibição de visita aos respectivos parreirais.

O maior problema para o cultivo desse tipo de fruta, tanto nos climas tropicais quanto na região Sul, é a umidade e a chuva. Nesse sentido, a busca por variedades mais resistentes está dentre os objetivos do projeto 'Uvas do Brasil' de melhoramento das videiras. Especificamente, em relação à Melina, há uma demanda por uma variedade que proporcione sabor e cor ao suco sem que haja a necessidade de misturar duas variedades distintas. Um dos problemas em misturar variedades é a diferença entre o tempo necessário para o amadurecimento da fruta, desencadeando queda de produtividade durante 0 processo.

Em suma, pode-se constatar que as novas variedades vão sendo pesquisadas e desenvolvidas à medida que ocorre a percepção de uma lacuna na cadeia produtiva - seja durante o cultivo ou no resultado das propriedades finais do suco - e quando se verifica a melhoria de uma nova variedade em relação à variedade anterior, é feita a substituição. Cabe enfatizar o relato do entrevistado sobre o apoio da Embrapa como aspecto fundamental para

Revista de Estudos Sociais | Ano 2017, N. 38, V. 19, Pag. 29 
decisão de abertura da Melina Agropecuária, colocando a pesquisa e o desenvolvimento de novas cultivares como pré-requisito para a possibilidade de plantar uva no estado.

Além disso, apesar da evidente dependência tecnológica em relação a Embrapa e do seu papel passivo na geração de tecnologia, o caso da Melina é semelhante ao que ocorre em outras regiões do país, mostrando-se uma característica do padrão setorial ao qual pertence. Para preencher a lacuna da inexistência de um sistema local de inovação - presente nos polos produtivos do Rio Grande Sul - a Melina apresenta vínculos fortes e de longo prazo com a Embrapa Uva e Vinho e seu Projeto de Melhoramento.

Dessa forma, em termos de dimensão do conhecimento, a situação da empresa em estudo é próxima ao verificado no Vale dos Vinhedos, conforme estudo de Jeziorny e Ortega (2013). O Vale dos Vinhedos caracteriza-se pela presença de um sistema local de inovação consolidado, em que os agentes trabalham de forma sistêmica. Além da Embrapa Uva e Vinho e o Centro de Educação Tecnológica, ambos localizados em Bento Gonçalves, trabalham em conjunto com a Universidade de Caxias do Sul, através do Instituto de Biotecnologia - Rede Nacional de Pesquisa em Levedura - vinícolas e agricultores familiares.

Em ambos os contextos, o conhecimento do tipo learning by doing é gerado através da atividade vitivinícola dos agricultores, que testam novas variedades e técnicas de cultivo; em consonância com o conhecimento codificado - learning by searching - gerado por parte da Embrapa, no caso da Melina, e das diversas instituições pertencentes ao sistema local de inovação, no caso da região do Rio Grande do Sul. (JEZIORNY, ORTEGA, 2013).

Salvo as firmas líderes, a maior parte das empresas realizam inovações informais, mediante 'tentativa e erro' na produção de suco e vinho (FARIAS, 2010). Assim, não apenas a Melina, mas todas as empresas que participam do projeto usufruem de vantagens, pois realizam inovações de forma sistemática, apropriando-se e absorvendo tecnologia com maior facilidade, em virtude do conhecimento tácito gerado nos processos de experimentação (CARVALHO et al., 2006).

Ademais, considerando também que a maior parte das empresas do setor produtor de suco e vinho enfocam as inovações no modelo de negócios e transferem a responsabilidade de inovação para os fornecedores de equipamentos e insumos químicos da produção industrial, a empresa investe no que, de acordo com os estudos na área, deveria ser o foco das firmas para melhorar a qualidade do produto final, a saber, a atividade agrícola. Segundo Farias (2010, p. 6), no setor, "a reconversão dos vinhedos não se dá pelo predomínio de uma lógica de custos de curto prazo", que implica em alto investimento inicial e redução de produtividade.

Por fim, cabe ressaltar que a cooperação entre a Melina e a Embrapa está em linha aos resultados de outros estudos de casos de interação no setor agrícola no estado de Mato Grosso. Em mais dois casos, as parcerias ocorreram com instituições de pesquisa localizadas fora do estado, com 0 objetivo de lançar e/ou testar novas cultivares, nas quais as instituições foram as responsáveis pela geração de conhecimento através de pesquisa e desenvolvimento. Entre 1998 e 2002, a parceria entre a Fundação MT e

Revista de Estudos Sociais | Ano 2017, N. 38, V. 19, Pag. 30 
Embrapa Cerrados foi importante para o lançamento de várias cultivares de soja e de sua divulgação juntos aos produtores (CARLI, 2005). No setor sucroalcooleiro, tem-se interação informal da Usina Barralcool com a Rede Interuniversitária para o Desenvolvimento do Setor Sucroenergético (Ridesa), na qual a empresa tem um papel passivo na geração de tecnologia, mas contribui testando as cultivares em parte da sua área produtiva (ALMEIDA et. al., 2011).

\section{Considerações Finais}

O caso do setor vitivinícola vem ilustrar aspectos importantes sobre a dinâmica tecnológica da agricultura brasileira. Em primeiro lugar, este estudo confirma que o impacto das pesquisas no setor produtivo é facilitado pela interação, sendo que as parcerias englobam mapeamento das necessidades dos empresários e agricultores, não somente quanto ao melhoramento genético, mas também no caso de indicação geográfica e técnicas de cultivo e manejo (JEZIORNY, ORTEGA, 2013).

A estrutura concorrencial de oligopólio concorrencial confere desvantagens de escala para os estabelecimentos de pequeno porte, sobretudo no caso do segmento industrial de suco de uva, caracterizado por baixas oportunidades de diferenciação de produto. Assim, as inovações de produto dependem do aprimoramento da qualidade da matéria-prima, ainda que a estratégia de certificação tenha motivado grande parte das inovações de processo e organizacionais do segmento industrial da Agropecuária Melina.

Em segundo lugar, fica evidente a importância das ações do Estado para a consolidação do sistema de inovação agrícola. $E$ apesar da perda da hegemonia da Embrapa nos segmentos mais competitivos (soja, milho, etc.) em virtude da ascensão recente do P\&D agrícola das megacorporações, suas pesquisas foram fundamentais para o desenvolvimento agrícola do país e da região Centro-Oeste ${ }^{14}$. No caso do setor vitivinícola, o padrão tecnológico atual está relacionado à trajetória das próprias instituições públicas de pesquisa, com a Embrapa mantendo a liderança no lançamento de novas cultivares. Um exemplo do reconhecimento da Embrapa Uva e Vinho como instituição de pesquisa de excelência em sua área de conhecimento é o forte potencial que as cultivares de uva apresentam quanto à demanda externa de países de clima quente, próximos ao do Brasil, e que não realizam esse tipo de pesquisa. (CAMARGO, 2008).

Dessa forma, o caso mostra que o sucesso da interação não se restringe a um acontecimento isolado ou a vantagens competitivas acidentais, provenientes de recursos naturais, mas, ao contrário, emerge da consolidação de um sistema setorial de inovação que remete a investimentos em pesquisa e recursos humanos iniciados no século XIX. Além disso, a transferência tecnológica dos institutos públicos de pesquisa mantém-se particularmente importante para competitividade da produção agrícola, com vantagens para

\footnotetext{
${ }_{14}$ As tecnologias desenvolvidas na área de fertilidade de solos e melhoramento genético contribuíram para o desenvolvimento do agronegócio no Cerrado e, consequentemente, para o dinamismo econômico recente da região.
}

Revista de Estudos Sociais | Ano 2017, N. 38, V. 19, Pag. 31 
aqueles estabelecimentos que funcionam como campo experimental, na medida em que aumenta sua capacidade de absorção da tecnologia. Isso ocorre tanto em segmentos menos competitivos, como é o caso do cultivo da uva, quanto naqueles em que o país se destaca em nível internacional, como a cana-de-açúcar ${ }^{15}$.

Por fim, são evidentes as vantagens das interações com institutos de pesquisa para o desenvolvimento do setor agrícola mato-grossense, que ocorre nas culturas de soja, cana-de-açúcar e, particularmente no caso da Melina, também no cultivo de uva. Além disso, o fato dos casos encontrados de interação relevante serem realizados com instituições de pesquisa localizadas fora do estado de Mato Grosso tem relação com incipiência das atividades de pesquisa nesta localidade. No que diz respeito às interações que ocorrem com grupos de pesquisa dentro do estado, estudo realizado com as empresas interativas da região revelou que área de ciências agrárias é a área de conhecimento mais importante como fonte de informação para inovações, de acordo com as firmas entrevistadas (ALMEIDA et. al., 2011). Há, portanto, a necessidade de realização de outros estudos de casos para aprofundar nas análises dos benefícios e impasses da interação local, para servir como subsídios de formulação e implementação de políticas que venham a estimular a proximidade entre os meios acadêmico empresarial no estado.

Referências

ALMEIDA, C. C. R.; VILLELA, T. C.; CARIO, A. F.; SEABRA, F. Interação universidade-empresa na região Centro-Oeste do Brasil: características de um sistema regional de inovação imaturo. Revista de Economia, Curitiba (PR), v. 37, n 4: volume especial, p.83-115, 2011.

BONACELLI, M.B.M.; FUCK, M.P; CASTRO, A.C. O Sistema de Inovação Agrícola: Instituições, Competências e Desafios do Contexto Brasileiro. In: BUAINAIN, A.M.; BONACELLI, M.B.M.; MENDES, C.I.C (Org) Propriedade Intelectual e Inovações na Agricultura. Brasília; Rio de Janeiro : CNPq, FAPERJ, INCT/PPED, IdeiaD ; p. 89-109, 2015.

CAMARGO, U. A. Impacto das cultivares brasileiras de uva no mercado interno e potencial no mercado internacional. In: XII Congresso Brasileiro de Viticultura e Enologia, 2008. Anais. Bento Gonçalves: Embrapa Uva e Vinho, 2008. Disponível em <http://ainfo.cnptia.embrapa.br/digital/bitstream/item/50641/1/CAMARGO2.pdf> Acesso em: 15 jul. 2014.

\footnotetext{
15 Como já comentado, no cultivo de cana-de-açúcar também predomina a transferência de tecnologia de instituições públicas de pesquisa para o setor produtivo. No entanto, devido a própria adaptação dessa cultura as condições naturais do estado do Mato Grosso, a interação contribui positivamente, mas não é determinante para a manutenção dessas atividades. Estudo sobre a interação universidade-empresa na Usina Barralcool mostrou que o papel da Ridesa é complementar (ALMEIDA et al., 2011), enquanto para a Agropecuária Melina a cooperação com a Embrapa foi fundamental para criação e assim tem sido para a continuidade das atividades da empresa no estado.
}

Revista de Estudos Sociais | Ano 2017, N. 38, V. 19, Pag. 32 
CAMARGO, E. A.; TONIETTO, J.; HOFFMANN, A. Progressos na viticultura brasileira. Revista Brasileira Fruticultura. Jaboticabal (SP), Volume Especial, E. 144-149, out. 2011.

CAMARGO, U. A.; MAIA, J. D. G.; RITSCHEL, P. S. BRS Carmem: Nova cultivar de uva tardia para suco. Comunicado Técnico 84. Bento Gonçalves (RS): Embrapa Uva e Vinho, 2008. Disponível em <https://www.cnpuv.embrapa.br/publica/comunicado/cot084.pdf> Acesso em: 05 ago. 2014.

CAMARGO, U. A.'Isabel Precoce': Alternativa para a Vitivinicultura Brasileira. Comunicado Técnico 54. Bento Gonçalves (RS): Embrapa Uva e Vinho, 2004. Disponível em <https://www.cnpuv.embrapa.br/publica/comunicado/cot054.pdf> Acesso em 05 ago. 2014.

CAMPOLINA, B. A estrutura do Sistema de Inovação em Ciências Agrárias no Brasil. In: DE NEGRI, F.; SQUEFF, F. H. S. (Org.) Sistemas Setoriais de Inovação e infraestrutura de pesquisa no Brasil. Brasília: IPEA, FINEP, CNPq, 2016.

CARLI, C. R. EMBRAPA: precursora da parceria público-privada no Brasil. 2005. Dissertação (Mestrado em Desenvolvimento Sustentável). Centro de Desenvolvimento Sustentável, Universidade de Brasília, Brasília, 2005.

CARVALHO, D. F. Padrões de concorrência e Estruturas de Mercado no Capitalismo (Uma abordagem neo-schumpeteriana). Paper do NAEA 142. Belém: Núcleo de Altos Estudos Amazônicos/UFPA, 2000.

CARVALHO, S. M. P.; SALLES-FILHO, S. L. M.; PAULINO, S. R. Propriedade Intelectual e Dinâmica de Inovação na Agricultura. Revista Brasileira de Inovação. Campinas (SP), v. 5, n. 2, jul./dez. 2006.

EMBRAPA LANÇA nova variedade de uva para produção de suco. MT Rural. TV Centro América, 24 nov. 2012. Programa de TV. Disponível em $<$ http://g1.globo.com/videos/mato-grosso/mt-rural/t/edicoes/v/embrapa-lancanova-variedade-de-uva-para-producao-de-suco/2257900/> Acesso em: 03 out. 2013.

EMBRAPA UVA E VINHO. Bento Gonçalves (RS), A Unidade. História. Disponível em <https://www.embrapa.br/uva-e-vinho/historia> Acesso em: 01 ago. 2014.

FARIAS, C. V. S. Inovação e ganhos competitivos na vitivinicultura gaúcha: uma abordagem preliminar. In: IV Encontro de Economia Catarinense, 2010.

Anais. Criciúma (SC): Associação de Pesquisadores em Economia Catarinense, $2010 . \quad$ Disponível em $<$ http://www.apec.unesc.net/IV EEC/sessoes tematicas/Economia\%20industria 1,\%20ci\%EAncia,\%20tecnologia\%20e\%20inova\%E7\%E3o/Inova\%e7\%e30\%20 e\%20ganhos\%20competitivos\%20na\%20vitivinicultura\%20ga\%facha\%20uma \%20abordagem\%20preliminar.pdf > Acesso em: 15 jul. 2014.

FREEMAN, C. The National systems of innovation in historical perspective. Cambridge Journal of Economics, v.19, n.1, p. 5-24, 1995. 
FRONZAGLIA, T.; GUEDES, V. G. F. FALCÃO, J. F. N. Interação da pesquisa tecnológica com vitivinicultores: aprendizagem e transbordamento da construção social de Indicação Geográfica. In: VIII Congresso Latino-americano de Sociologia Rural, 2010. Anais. Porto de Galinhas (PE): ALASRU, 2010.

HOFFMANN, A. Contribuições da Embrapa Uva e Vinho à inovação tecnológica no cultivo de pequenas frutas de clima temperado. In: Seminário Brasileiro sobre Pequenas Frutas, 4, 2007. Anais. Vacaria, (RS), Embrapa Uva e Vinho, 2007. 71 p.

HOFFMANN, A.; CAMARGO, U. A.; MAIA, J. D. G. Sistema de Produção de Uvas Rústicas para Processamento em Regiões Tropicais do Brasil. Sistemas de Produção, 9. Versão Eletrônica. Embrapa Uva e Vinho: dez. 2005. Disponível

em <http://www.cnpuv.embrapa.br/publica/sprod/UvasRusticasParaProcessamento /index.htm> Acesso em: 01 ago. 2014.

INSTITUTO NACIONAL DA PROPRIEDADE INDSUTRIAL - INPI. Registros Indicação Geográfica. 26/08/2014. Disponível em http://www.inpi.gov.br/images/docs/lista com as indicacoes geograficas conc edidas - 26-08-2014.pdf Acesso em: 30 ago. 2014.

JEZIORNY; D. L.; ORTEGA, A. C. Inovação e performance competitiva na indústria vitivinícola brasileira. Ensaios FEE, Porto Alegre (RS), v. 33, Número Especial, p. 865-886, 2013.

JUK, Y. V.; FUCK, M. P. Indicações geográficas e inovações: um estudo de caso no Vale dos Vinhedos. In: BUAINAIN, A.M.; BONACELLI, M.B.M.; MENDES, C.I.C (Org) Propriedade Intelectual e Inovações na Agricultura. Brasília; Rio de Janeiro: CNPq, FAPERJ, INCT/PPED, IdeiaD; p. 187-206, 2015.

MELINA AGROPECUÁRIA. Fazenda, Imagens, Notícias e Produtos. 2013. Disponível em <http://www.sucodeuvamelina.com.br>. Acesso em: 05 jun. 2013.

MENDES, C. I. C.; BUAINAIN, A. M.; FASIABEN, M. C. R. Transferência de tecnologias geradas pela Embrapa: condicionantes exógenos. In: BUAINAIN, A.M.; BONACELLI, M.B.M.; MENDES, C.I.C (Org) Propriedade Intelectual e Inovações na Agricultura. Brasília; Rio de Janeiro: CNPq, FAPERJ, INCT/PPED, IdeiaD; p. 165-183, 2015.

MENDES, I. C.; RODRIGUES, L. C.; SILVEIRA, A.; NASCIMENTO, S. A Presença da Inovação: Modelo de Negócios na Casa Valduga. In: XXXVI Encontro da Anpad, 2012. Anais. Rio de Janeiro, 22 a 26 set. 2012.

PERES, M. Nova variedade é industrializada. Diário de Cuiabá. Cuiabá (MT), 22 ago. 2004.2 Disponível em <http://www.diariodecuiaba.com.br/detalhe.php?cod=191098\%5D\%3Cb> Acesso em: 10 jun. 2013.

PORTAL MATO GROSSO. Nova Mutum. Mapa do Município. Cuiabá (MT). Disponível em 
http://www.mteseusmunicipios.com.br/NG/conteudo.php?sid=184\&cid=2512> Acesso em 05 jun. 2013.

POSSAS, M. L.; SALLES-FILHO, S.; SILVEIRA, J. M. An evolutionary approach to technological innovation in agriculture: some preliminary remarks. Research policy, v. 25, n. 6, p. 933-945, 1996.

PROTAS, J. F. S.; CAMARGO, U. C. Vitivinicultura brasileira - panorama setorial em 2010. Versão digital. Brasília (DF): SEBRAE; Bento Gonçalves: IBRAVIN: Embrapa Uva e Vinho, 2011. Disponível em http://www.ibravin.org.br/public/upload/downloads/1384347732.pdf Acesso em: 10 ago. 2014.

SLUSZZ, T.; PADILHA, A. C. M. Estratégias de internacionalização dos espumantes: um estudo de cinco vinícolas do Rio Grande do Sul. Revista Brasileira de Gestão e Desenvolvimento Regional. Taubaté (SP), v. 4, n. 4, p. 3-24, set./dez. 2008.

SUZIGAN, W; ALBUQUERQUE, E. M. The underestimated role of universities for the Brazilian system of innovation. Brazilian Journal of Political Economy, v. 31, n 1, 121, p. 3-30, 2011.

TEIXEIRA, E. C.; CLEMENTE, F.; BRAGA, M. A contribuição das universidades para o desenvolvimento da agricultura no Brasil. Revista de Economia e Agronegócio, v.11, n. 1, p. 237-157, 2013.

UVAS DO BRASIL. Programa de Melhoramento Genético. Apresentação. Bento Gonçalves (RS), Embrapa Uva e Vinho, 2014a. Disponível em $<$ http://www.cnpuv.embrapa.br/pesquisa/pmu/index.php?opcao=opt $02>$ Acesso em: 01 ago. 2014.

. Programa de Melhoramento Genético. Parceiros. Bento Gonçalves (RS), Embrapa Uva e Vinho, 2014b. Disponível em <http://www.cnpuv.embrapa.br/pesquisa/pmu/index.php?opcao=opt_07> Acesso em: 01 ago. 2014.

VIEIRA, P. A.; BUAINAIN, A. M.; TORRES, D. A. P.; CONTINI, E. A Embrapa e seu papel no sistema nacional de inovação agrícola. In: BUAINAIN, A.M.; BONACELLI, M.B.M.; MENDES, C.I.C (Org) Propriedade Intelectual e Inovações na Agricultura. Brasília; Rio de Janeiro: CNPq, FAPERJ, INCT/PPED, IdeiaD; p. 135-164, 2015. 